\title{
Predictive factors for hyperglycaemic progression in patients with schizophrenia or bipolar disorder
}

Ichiro Kusumi, Yuki Arai, Ryo Okubo, Minoru Honda, Yasuhiro Matsuda, Yukihiko Matsuda, Akihiko Tochigi, Yoshiteru Takekita, Hiroyoshi Yamanaka, Keiichi Uemura, Koichi Ito, Kiyoshi Tsuchiya, Jun Yamada, Bunta Yoshimura, Nobuyuki Mitsui, Sigehiro Matsubara, Takayuki Segawa, Nobuyuki Nishi, Yasufumi Sugawara, Yuki Kako, Ikuta Shinkawa, Kaoru Shinohara, Akiko Konishi, Junichi Iga, Naoki Hashimoto, Shinsaku Inomata, Noriko Tsukamoto, Hiroto Ito, Yoichi M. Ito and Norihiro Sato

\section{Background}

Patients with schizophrenia or bipolar disorder have a high risk of developing type 2 diabetes.

\section{Aims}

To identify predictive factors for hyperglycaemic progression in individuals with schizophrenia or bipolar disorder and to determine whether hyperglycaemic progression rates differ among antipsychotics in regular clinical practice.

\section{Method}

We recruited 1166 patients who initially had normal or prediabetic glucose levels for a nationwide, multisite, I-year prospective cohort study to determine predictive factors for hyperglycaemic progression. We also examined whether hyperglycaemic progression varied among patients receiving monotherapy with the six most frequently used antipsychotics.

\section{Results}

High baseline serum triglycerides and coexisting hypertension significantly predicted hyperglycaemic progression. The six most frequently used antipsychotics did not significantly differ in their associated hyperglycaemic progression rates over the 1-year observation period.

\section{Conclusions}

Clinicians should carefully evaluate baseline serum triglycerides and coexisting hypertension and perform strict longitudinal monitoring irrespective of the antipsychotic used.

\section{Declaration of interest}

The authors report no financial or other relationship that is relevant to the subject of this article. Relevant financial activities outside the submitted work are as follows. I.K. has received honoraria from Astellas, Chugai Pharmaceutical, Daiichi Sankyo, Dainippon Sumitomo Pharma, Eisai, Eli Lilly, Janssen Pharmaceutical, Kyowa Hakko Kirin, Meiji Seika Pharma, MSD, Nippon Chemiphar, Novartis Pharma, Ono Pharmaceutical,
Otsuka Pharmaceutical, Pfizer, Tanabe Mitsubishi Pharma, Shionogi and Yoshitomiyakuhin; has received research/grant support from AbbVie GK, Asahi Kasei Pharma, Astellas, Boehringer Ingelheim, Chugai Pharmaceutical, Daiichi Sankyo, Dainippon Sumitomo Pharma, Eisai, Eli Lilly, GlaxoSmithKline, Kyowa Hakko Kirin, Meiji Seika Pharma, MSD, Novartis Pharma, Ono Pharmaceutical, Otsuka Pharmaceutical, Pfizer, Takeda Pharmaceutical, Tanabe Mitsubishi Pharma, Shionogi and Yoshitomiyakuhin; and is a member of the advisory boards of Dainippon Sumitomo Pharma and Tanabe Mitsubishi Pharma. Y. T. has received speaker's honoraria from Dainippon-Sumitomo Pharma, Otsuka, Meiji-Seika Pharma, Janssen Pharmaceutical, Daiichi-Sankyo Company, UCB Japan and Ono Pharmaceutical. K. $U$. has received honoraria from Dainippon Sumitomo Pharma, Eisai, Eli Lilly, Janssen Pharmaceutical, Kyowa Hakko Kirin, Meiji Seika Pharma, MSD, Takeda Pharmaceutical, Hisamitsu Pharmaceutical, Otsuka Pharmaceutical, Pfizer, Tanabe Mitsubishi Pharma, Shionogi and Yoshitomiyakuhin. B.Y. has received speaker's honoraria from Otsuka Pharmaceutical and Janssen Pharmaceutical. J. I. has received honoraria from Dainippon Sumitomo Pharma, Eli Lilly, Janssen Pharmaceutical, Meiji Seika Pharma, MSD, Novartis Pharma, Otsuka Pharmaceutical and Mochida Pharma.

\section{Keywords}

Schizophrenia; bipolar disorder; diabetes; monitoring.

\section{Copyright and usage}

(C) The Royal College of Psychiatrists 2018. This is an Open Access article, distributed under the terms of the Creative Commons Attribution-NonCommercial-NoDerivatives licence (http://creativecommons.org/licenses/by-nc-nd/4.0/), which permits noncommercial re-use, distribution, and reproduction in any medium, provided the original work is unaltered and is properly cited. The written permission of Cambridge University Press must be obtained for commercial re-use or in order to create a derivative work.
Individuals with schizophrenia or bipolar disorder have life expectancies that are 15-20 years shorter than average. ${ }^{1}$ Autopsies indicate that the most common cause of sudden death in patients with schizophrenia is cardiovascular disease, especially myocardial infarction. ${ }^{2,3}$ Compared with age- and gender-matched controls, patients with schizophrenia or bipolar disorder are at least twice as likely to develop type 2 diabetes, ${ }^{4,5}$ which is a risk factor for cardiovascular disease. ${ }^{6}$ Some antipsychotic medications including second-generation antipsychotics can lead to substantial weight gain, ${ }^{7}$ which increases the risk of dyslipidaemia and diabetes. ${ }^{8,9}$ Thus, patients with schizophrenia or bipolar disorder who are receiving antipsychotics should be appropriately monitored for the development of cardiovascular risk factors such as obesity and diabetes.
Few cross-sectional studies have examined the prevalence of glucose abnormalities in patients with schizophrenia. ${ }^{10-12}$ Crosssectional studies are relatively easy to perform and permit the recruitment of many participants, but they do not clearly establish causality. Ideally, longitudinal pharmacogenetic studies of metabolic effects should recruit hundreds or thousands of patients and follow them for years, but doing so is difficult and expensive. ${ }^{13}$ Prospective data from the Clinical Antipsychotic Trials of Intervention Effectiveness (CATIE) schizophrenia trial indicated that of the second-generation antipsychotics, olanzapine causes the most metabolic side-effects and ziprasidone causes the least. ${ }^{14}$ These results confirmed that second-generation antipsychotics differ in their metabolic impacts. We previously conducted a longitudinal study of glucose abnormalities in patients with 
schizophrenia treated with second-generation antipsychotics, ${ }^{15}$ but that study had several limitations, including a retrospective design, the inclusion of patients who were not starting a new antipsychotic at the beginning of the study, a lack of medication history or monitoring of co-administered drugs during the pre-entry and study periods, the exclusion of patients receiving first-generation antipsychotics and recruitment from a small geographic area. We thus sought to conduct a more sophisticated study to overcome these limitations. Several countries have recently developed guidelines for the routine monitoring of body weight, serum lipids and blood glucose in patients with schizophrenia. ${ }^{16,17}$ These guidelines are expected to improve the detection and prevention of diabetes and other glucose abnormalities. We similarly proposed a method for monitoring blood glucose in patients with schizophrenia receiving second-generation antipsychotics in Japan. ${ }^{10}$ However, few guidelines have been proposed to prevent glucose-related abnormalities in patients with bipolar disorder. Accordingly, we conducted a nationwide, multisite, 1-year prospective cohort study using the Japanese blood glucose monitoring guidelines in order to identify predictive factors for hyperglycaemia in patients treated with antipsychotics who have schizophrenia, schizoaffective disorder or bipolar disorder. We also examined the effects of antipsychotics on hyperglycaemic progression to test our hypothesis that regular monitoring is necessary even in patients taking lowrisk antipsychotics.

\section{Method}

\section{Study population}

Individuals were diagnosed with schizophrenia, schizoaffective disorder or bipolar disorder based on the criteria in ICD-10. ${ }^{18}$ The inclusion criteria were initiation of a first- or second-generation antipsychotic medication (either by changing medications or adding a new medication), a 1-year medication history prior to enrolment, no diagnosis of diabetes prior to baseline screening and not being classified as probable diabetes at baseline monitoring. Participant selection was consecutive at each site. All participants provided written informed consent after receiving a full explanation of the study procedures.

\section{Study design}

Participants were enrolled between April 2013 and March 2015 and followed-up for 1 year based on the Japanese blood glucose monitoring guidelines for patients with schizophrenia. ${ }^{10}$ The study was conducted at 44 sites ( 24 general hospitals, 17 psychiatric hospitals and 3 psychiatric clinics) throughout Japan, was approved by each site's institutional review board and conformed to the principles of the Declaration of Helsinki. Data were collected through an electronic database system (CapTool Prime; Mebix, Tokyo, Japan) and managed at the Hokkaido University Hospital Clinical Research and Medical Innovation Center. For thorough follow-up data collection, researchers received notices about missing data from the data management centre when the monitoring period was over.

To identify predictive factors for hyperglycaemic progression in patients with normal or prediabetic baseline glucose levels, we first examined the number of patients who progressed from normal glucose levels to prediabetes or probable diabetes and the number who progressed from prediabetes to probable diabetes during the 1 -year follow-up period. We then conducted a Cox regression analysis using demographic data and monitoring measurements. Moreover, to examine the effects of antipsychotics on hyperglycaemic progression during the follow-up period, we compared how frequently classifications became at least one step worse (i.e. from normal glucose levels to prediabetes or probable diabetes, or from prediabetes to probable diabetes) among patients receiving monotherapy with any of the six antipsychotics most frequently used in our study.

\section{Assessments}

In the initial screenings, we obtained participant demographic characteristics including age, gender, illness duration, out-patient versus in-patient status, smoking status, drinking status, familial disease histories (including schizophrenia, bipolar disorder, major depressive disorder, diabetes mellitus and dyslipidaemia), coexisting medical diagnoses (including hypertension, heart disease and dyslipidaemia), and 1-year medication histories prior to enrolment and during the study period. Before the initiation of a new antipsychotic, we obtained baseline measurements of blood glucose (fasting or postprandial) or glycated haemoglobin $\left(\mathrm{Hb}_{\mathrm{Alc}}\right)$, serum lipids (total cholesterol, high-density lipoprotein (HDL)-cholesterol and triglycerides), weight, body mass index (BMI) and clinical diabetic symptoms such as dry mouth, excessive fluids consumption, cravings for sugary drinks, polyuria and frequent urination.

According to the Japanese guidelines for blood glucose monitoring in patients with schizophrenia, ${ }^{10}$ patients' blood glucose measurements were classified as normal, prediabetic or probably diabetic. Normal was defined as fasting blood glucose $<110 \mathrm{mg} /$ $\mathrm{dL}$, postprandial blood glucose $<140 \mathrm{mg} / \mathrm{dL}$ or $\mathrm{Hb}_{\mathrm{Alc}}<6.0 \%$; prediabetes was defined as fasting blood glucose of $110-125 \mathrm{mg} / \mathrm{dL}$, postprandial blood glucose of $140-179 \mathrm{mg} / \mathrm{dL}$ or $\mathrm{Hb}_{\mathrm{Alc}}$ of $6.0-$ $6.4 \%$; and probable diabetes was defined as fasting blood glucose $>125 \mathrm{mg} / \mathrm{dL}$, postprandial blood glucose $>179 \mathrm{mg} / \mathrm{dL}$ or $\mathrm{Hb}_{\mathrm{Alc}}$ $>6.4 \%$. Because these classifications permit the early detection of possible diabetes, declassification is never allowed even if normal measurement values are recovered. The follow-up measurements were also scheduled according to the Japanese monitoring guidelines ${ }^{10}$ and were conducted at months 3, 6 and 12 in patients with normal glucose levels; months 1, 3, 6, 9 and 12 in patients with prediabetes; and every month in patients with probable diabetes.

\section{Statistical analysis}

We used a Cox proportional-hazards regression model ${ }^{19}$ to identify predictive factors for hyperglycaemic progression. It accounted for demographic variables including gender; age; diagnosis (schizophrenia/schizoaffective disorder versus bipolar disorder); duration of illness; treatment status (out-patient versus in-patient); smoker status; drinker status; familial histories of schizophrenia, bipolar disorder, major depression, diabetes and heart disease; coexisting diagnoses of dyslipidaemia, hypertension and heart disease; baseline measurements including weight, BMI $(<25 v . \geq 25)$, total cholesterol $(<220 v . \geq 220 \mathrm{mg} / \mathrm{dL})$, HDL-cholesterol $(<40 v . \geq 40 \mathrm{mg} / \mathrm{dL})$ and triglycerides $(<150 v . \geq 150 \mathrm{mg} / \mathrm{dL})$; clinical diabetes symptoms such as dry mouth, excessive fluids consumption, craving for sugary drinks, polyuria and frequent urination; and medications at baseline (second- or first-generation antipsychotics pre-administrated with a newly initiated antipsychotic drug). Statistical significance was evaluated with likelihood ratio and hazard ratio (HR) tests with 95\% profile likelihood confidence interval.

To examine the effects of antipsychotic monotherapy on hyperglycaemic progression, we estimated the hyperglycaemic progression rate as $15 \%$ based on our previous study. ${ }^{15}$ For a two-sided confidence interval of a binomial proportion whose true value was 0.15 , a sample size of 196 yielded a maximal half-width of 0.05 . We estimated that $40 \%$ of patients used one of the six most commonly used second-generation antipsychotics and that $50 \%$ of patients continued monotherapy for more than 10 months. Since 
Table 1 Participant characteristics and baseline monitoring and medication

\begin{tabular}{|c|c|c|c|c|c|c|}
\hline & \multicolumn{3}{|c|}{ Value } & \multicolumn{3}{|c|}{$n$} \\
\hline & Total & $\begin{array}{l}\text { Schizophrenia/ } \\
\text { schizoaffective } \\
\text { disorder }\end{array}$ & $\begin{array}{l}\text { Bipolar } \\
\text { disorder }\end{array}$ & $\begin{array}{c}\text { Total } \\
(n=1166)^{\mathrm{a}}\end{array}$ & $\begin{array}{c}\text { Schizophrenia/ } \\
\text { schizoaffective } \\
\text { disorder }(n=982)^{\text {a }}\end{array}$ & $\begin{array}{c}\text { Bipolar } \\
\text { disorder } \\
(n=184)^{\mathrm{a}}\end{array}$ \\
\hline \multicolumn{7}{|l|}{ Characteristics } \\
\hline Man/woman, $n$ (\%) & $512(43.9) / 654(56.1)$ & $436(44.4) / 546(55.6)$ & $76(41.3) / 108(58.7)$ & 1166 & 982 & 184 \\
\hline Age, years: mean (s.d.) & $48.4(16.7)$ & $47.9(16.8)$ & $51.1(15.7$ & 1166 & 982 & 184 \\
\hline $\begin{array}{l}\text { Duration of illness, years: mean } \\
\text { (s.d.) }\end{array}$ & $16.6(14.5)$ & $17.3(15.0)$ & $13.0(11.1)$ & 1052 & 881 & 171 \\
\hline Out-patient/in-patient, $n$ (\%) & $558(47.9) / 608(52.1)$ & $431(43.9) / 551(56.1)$ & $127(69.0) / 57(31.0)$ & 1166 & 982 & 184 \\
\hline Smoking, $n(\%)$ & $334(29.2)$ & $275(28.5)$ & $59(32.8)$ & 1145 & 965 & 180 \\
\hline Drinking, $n$ (\%) & $184(16.1)$ & $141(14.7)$ & $43(23.8)$ & 1141 & 960 & 181 \\
\hline \multicolumn{7}{|l|}{ Familial history, $n$ (\%) } \\
\hline Schizophrenia & $147(14.1)$ & 135 (15.4) & $12(7.2)$ & 1043 & 876 & 167 \\
\hline Bipolar disorder & $32(3.1)$ & $17(2.0)$ & $15(9.0)$ & 1027 & 861 & 166 \\
\hline Major depression & $101(9.9)$ & $66(7.7)$ & 35 (21.3) & 1022 & 858 & 164 \\
\hline Diabetes & $197(20.3)$ & 159 (19.5) & $38(24.7)$ & 971 & 817 & 154 \\
\hline Dyslipidaemia & $89(9.7)$ & $76(9.8)$ & $13(9.4)$ & 914 & 775 & 139 \\
\hline \multicolumn{7}{|l|}{ Coexisting medical diagnoses, $n$ (\%) } \\
\hline Dyslipidaemia & $163(14.0)$ & $130(13.3)$ & $33(18.0)$ & 1161 & 978 & 183 \\
\hline Hypertension & $139(12.0)$ & $106(10.9)$ & $33(18.1)$ & 1159 & 977 & 182 \\
\hline Heart disease & $58(5.0)$ & $42(4.3)$ & $16(8.8)$ & 1160 & 978 & 182 \\
\hline \multicolumn{7}{|l|}{ Monitoring at baseline } \\
\hline Body weight, kg: mean (s.d.) & $61.6(15.0)$ & $61.6(15.2)$ & $61.6(14.2)$ & 1160 & 978 & 182 \\
\hline Body mass index, kg/m²: mean (s.d.) & $23.6(4.8)$ & $23.6(4.8)$ & $23.7(4.6)$ & 1157 & 975 & 182 \\
\hline Body mass index $\geq 25, n(\%)$ & $381(32.9)$ & $318(32.6)$ & $63(34.6)$ & & & \\
\hline $\begin{array}{l}\text { Fasting blood glucose, mg/dL: mean } \\
\text { (s.d.) }\end{array}$ & $87.9(10.2)$ & $87.7(10.2)$ & $89.2(10.2)$ & 323 & 279 & 44 \\
\hline $\begin{array}{l}\text { Postprandial blood glucose, mg/dL: } \\
\text { mean (s.d.) }\end{array}$ & $102.8(20.4)$ & $103.4(20.6)$ & $99.7(19.2)$ & 835 & 696 & 139 \\
\hline HbA1c, \%: mean (s.d.) & $5.35(0.38)$ & $5.36(0.38)$ & $5.28(0.38)$ & 1130 & 950 & 180 \\
\hline Total cholesterol, mg/dL: mean (s.d.) & $188(39)$ & $187(38)$ & $196(40)$ & 1133 & 955 & 178 \\
\hline Total cholesterol $\geq 220, n(\%)$ & $234(20.7)$ & $194(20.3)$ & $40(22.4)$ & & & \\
\hline HDL-cholesterol, mg/dL: mean (s.d.) & $57.8(17.3)$ & $57.6(17.2)$ & $59.0(17.6)$ & 1109 & 930 & 179 \\
\hline HDL-cholesterol <40, $n(\%)$ & $128(11.5)$ & $111(11.9)$ & $17(9.5)$ & & & \\
\hline Triglyceride, mg/dL: mean (s.d.) & $120(83)$ & $119(86)$ & $128(69)$ & 1142 & 959 & 183 \\
\hline Triglyceride $\geq 150, n(\%)$ & $260(22.8)$ & $203(21.2)$ & $57(31.1)$ & & & \\
\hline \multicolumn{7}{|l|}{ Clinical diabetic symptoms, $n$ (\%) } \\
\hline Dry mouth & $209(18.1)$ & $178(18.3)$ & $31(16.8)$ & 1156 & 972 & 184 \\
\hline Excessive fluids consumption & 155 (13.4) & $130(13.3)$ & $25(13.6)$ & 1159 & 974 & 184 \\
\hline Cravings for sugar drinks & $128(11.0)$ & 116 (11.9) & $12(6.5)$ & 1159 & 975 & 184 \\
\hline Polyuria & $78(6.8)$ & $63(6.5)$ & $15(8.2)$ & 1155 & 971 & 184 \\
\hline Frequent urination & $120(10.4)$ & $96(9.9)$ & $24(13.0)$ & 1156 & 972 & 184 \\
\hline Classified type, $n$ (\%) & & & & 1166 & 982 & 184 \\
\hline Normal & $1042(89.4)$ & $875(89.1)$ & $167(90.8)$ & & & \\
\hline Prediabetes & $124(10.6)$ & $107(10.9)$ & $17(9.2)$ & & & \\
\hline Medication at baseline & & & & 1166 & 982 & 184 \\
\hline Newly initiated antipsychotics, $n$ (\%) & & & & 1166 & 982 & 184 \\
\hline Aripiprazole & $298(25.6)$ & $207(21.1)$ & $91(49.5)$ & & & \\
\hline Olanzapine & $193(16.6)$ & $123(12.5)$ & $70(38.0)$ & & & \\
\hline Quetiapine & $129(11.1)$ & $129(13.1)$ & & & & \\
\hline Blonanserin & $98(8.4)$ & $98(10.0)$ & & & & \\
\hline Risperidone & $96(8.2)$ & $96(9.8)$ & & & & \\
\hline Perospirone & $87(7.5)$ & $87(8.9)$ & & & & \\
\hline Levomepromazine & $70(6.0)$ & $56(5.7)$ & $14(7.6)$ & & & \\
\hline Paliperidone & $51(4.4)$ & $51(5.2)$ & & & & \\
\hline Haloperidol & $36(3.1)$ & $32(3.3)$ & $4(2.2)$ & & & \\
\hline Clozapine & $31(2.7)$ & 31 (3.2) & & & & \\
\hline Sulpiride & $26(2.2)$ & $23(2.3)$ & $3(1.6)$ & & & \\
\hline Zotepine & $16(1.3)$ & $16(1.6)$ & & & & \\
\hline Other first-generations & $35(3.0)$ & $33(3.4)$ & $2(1.1)$ & & & \\
\hline $\begin{array}{l}\text { Co-administered antipsychotics, } \\
\quad n(\%)\end{array}$ & & & & 1166 & 982 & 184 \\
\hline 0 & $540(46.3)$ & $414(42.2)$ & $126(68.5)$ & & & \\
\hline 1 & $409(35.1)$ & $362(36.9)$ & 47 (25.5) & & & \\
\hline$\geq 2$ & $217(18.6)$ & $206(21.0)$ & $11(6.0)$ & & & \\
\hline $\begin{array}{l}\text { Co-administered } \\
\text { non-antipsychotics, } n \text { (\%) }\end{array}$ & & & & 1166 & 982 & 184 \\
\hline Lithium & $79(6.8)$ & $34(3.5)$ & $45(24.4)$ & & & \\
\hline Valproate & $153(13.1)$ & $105(10.7)$ & $48(26.1)$ & & & \\
\hline Other mood stabilisers & $60(5.1)$ & $42(4.3)$ & $18(9.8)$ & & & \\
\hline
\end{tabular}




\begin{tabular}{|c|c|c|c|c|c|c|}
\hline & \multicolumn{3}{|c|}{ Value } & \multicolumn{3}{|c|}{$n$} \\
\hline & Total & $\begin{array}{l}\text { Schizophrenia/ } \\
\text { Schizoaffective } \\
\text { disorder }\end{array}$ & $\begin{array}{l}\text { Bipolar } \\
\text { disorder }\end{array}$ & $\begin{array}{c}\text { Total } \\
(n=1166)^{\mathrm{a}}\end{array}$ & $\begin{array}{c}\text { Schizophrenia/ } \\
\text { Schizoaffective } \\
\text { disorder }(n=982)^{\text {a }}\end{array}$ & $\begin{array}{l}\text { Bipolar } \\
\text { disorder } \\
(n=184)^{a}\end{array}$ \\
\hline SSRI & $76(6.5)$ & $48(4.9)$ & $28(15.2)$ & & & \\
\hline SNRI & $55(4.7)$ & $30(3.1)$ & $25(13.6)$ & & & \\
\hline Mirtazapine & $51(4.4)$ & $28(2.9)$ & $23(12.5)$ & & & \\
\hline Trazodone & $27(2.3)$ & $19(1.9)$ & $8(4.3)$ & & & \\
\hline Other antidepressants & $31(2.7)$ & $17(1.8)$ & $14(7.6)$ & & & \\
\hline
\end{tabular}

$10 \%$ of participants were on a first-generation antipsychotic, the minimum necessary sample size was estimated at 1089 .

To examine the effects of antipsychotics on hyperglycaemic progression, we selected patients with normal or prediabetic baseline glucose levels who received antipsychotic monotherapy for more than 10 months. We used the two -sided Fisher's exact test to determine whether the baseline frequencies of prediabetes and hyperglycaemic progression rates during the 1-year period depended on the antipsychotic used among patients receiving monotherapy with any of the six most frequently used antipsychotics in this study. Statistical significance was defined as $P<0.05$. Analyses were conducted using JMP Pro 13.1.0 (SAS Institute, Cary, NC).

\section{Results}

\section{Participants}

We performed inclusion screenings on 1323 patients with schizophrenia, schizoaffective disorder or bipolar disorder who had started treatment with a first- or second-generation antipsychotic. Of them, 77 declined to participate, 41 failed to meet the inclusion criteria, and 3 were rejected as duplicate enrolments. Because 36 patients who were classified as probably diabetic at baseline monitoring were removed from analysis, the final sample included 1166 patients (512 men and 654 women; mean age 48.4 years, s.d. $=16.7)$ whose various characteristics are shown in Table 1. Of the participants, $982(84.2 \%)$ were diagnosed with schizophrenia or schizoaffective disorder and $184(15.8 \%)$ were diagnosed with bipolar disorder. Of the six antipsychotics examined, aripiprazole was the most frequently prescribed as a starting drug (25.6\%), followed by olanzapine (16.6\%). At the study's initiation, 540 patients (46.3\%) started treatment with antipsychotic monotherapy.

\section{Blood glucose classifications}

At baseline, 1042 patients (89.4\%) were normal and 124 (10.6\%) were prediabetic (Table 1$)$. In total, 1018 participants $(87.3 \%)$ completed the 1-year follow-up period, and their glucose level classification changes are shown in Table 2. Of the 1042 patients whose results were initially normal, 116 became prediabetic $(12.6 \%)$ and 20 became probably diabetic (2.2\%). Of the 124 patients who were initially prediabetic, 18 became probably diabetic $(18.8 \%)$.

\section{Predictive factors for hyperglycaemic progression}

The simple Cox regression analysis identified significant predictive factors including age $(\mathrm{HR}=1.02,95 \% \mathrm{CI} 1.01-1.02, P=0.001)$; familial histories of schizophrenia $(\mathrm{HR}=0.65,95 \%$ CI $0.38-1.04$, $P=0.007)$; coexisting dyslipidaemia ( $\mathrm{HR}=1.69,95 \% \mathrm{CI} 1.15-2.42$, $P=0.008)$, hypertension $(\mathrm{HR}=1.93,95 \% \mathrm{CI} 1.30-2.78, P=0.002)$ and heart disease $(\mathrm{HR}=2.09,95 \% \mathrm{CI} 1.15-3.47, P=0.017)$; and baseline BMI (HR $=1.39,95 \%$ CI 1.02-1.87, $P=0.037)$ and serum triglycerides $(\mathrm{HR}=1.62,95 \% \mathrm{CI} 1.16-2.23, P=0.005)$ (Table 3$)$. The multivariate Cox regression analysis indicated that coexisting hypertension ( $\mathrm{HR}=1.80,95 \% \mathrm{CI} 1.01-3.13, P=0.048)$ and baseline serum triglycerides $(\mathrm{HR}=1.94,95 \% \mathrm{CI} 1.22-3.03, P=0.006)$ were significant predictors of hyperglycaemic progression during the study period (Table 3).

\section{Effects of antipsychotics on hyperglycaemic progression}

Among the patients who were taking any of the six most frequently used antipsychotics, there were no significant between-antipsychotic differences in the frequencies of baseline prediabetes (aripiprazole, $10 \%$; olanzapine, $11 \%$; quetiapine, $9 \%$; risperidone, $23 \%$; perospirone, $13 \%$; blonanserin, $11 \%$; $P=0.67$ ) or the hyperglycaemic progression rates over the study period (aripiprazole, 15\%; olanzapine, $20 \%$; quetiapine, $26 \%$; risperidone, $5 \%$; perospirone, $13 \%$; blonanserin, 22\%; $P=0.42$ ) (Table 4).

\section{Discussion}

\section{Principal findings}

We aimed to identify clinical predictors for hyperglycaemic progression in patients treated with antipsychotics who had

Table 2 Changes in prediabetes and probable diabetes rates during the 1-year follow-up period

\begin{tabular}{|c|c|c|c|}
\hline \multirow[b]{2}{*}{ Baseline classification ( $n$ ) and classification at follow-up } & \multicolumn{3}{|c|}{$n(\%)$} \\
\hline & Month $3(n=1159)$ & Month $6(n=1088)$ & Month $12(n=1018)$ \\
\hline \multicolumn{4}{|l|}{ Baseline classification: normal $^{a}$} \\
\hline Normal & $982(94.3)$ & $868(88.8)$ & $786(85.2)$ \\
\hline Prediabetes & $47(4.5)$ & $97(9.9)$ & $116(12.6)$ \\
\hline Probable diabetes & $12(1.2)$ & $13(1.3)$ & $20(2.2)$ \\
\hline \multicolumn{4}{|l|}{ Baseline classification: prediabetes ${ }^{a}$} \\
\hline Prediabetes & 109 (92.4) & $95(86.4)$ & 78 (81.3) \\
\hline Probable diabetes & $9(7.6)$ & $15(13.6)$ & $18(18.8)$ \\
\hline
\end{tabular}


Table 3 Cox regression analysis for predictive factors of hyperglycaemic progression in patients with normal or prediabetic baseline glucose levels

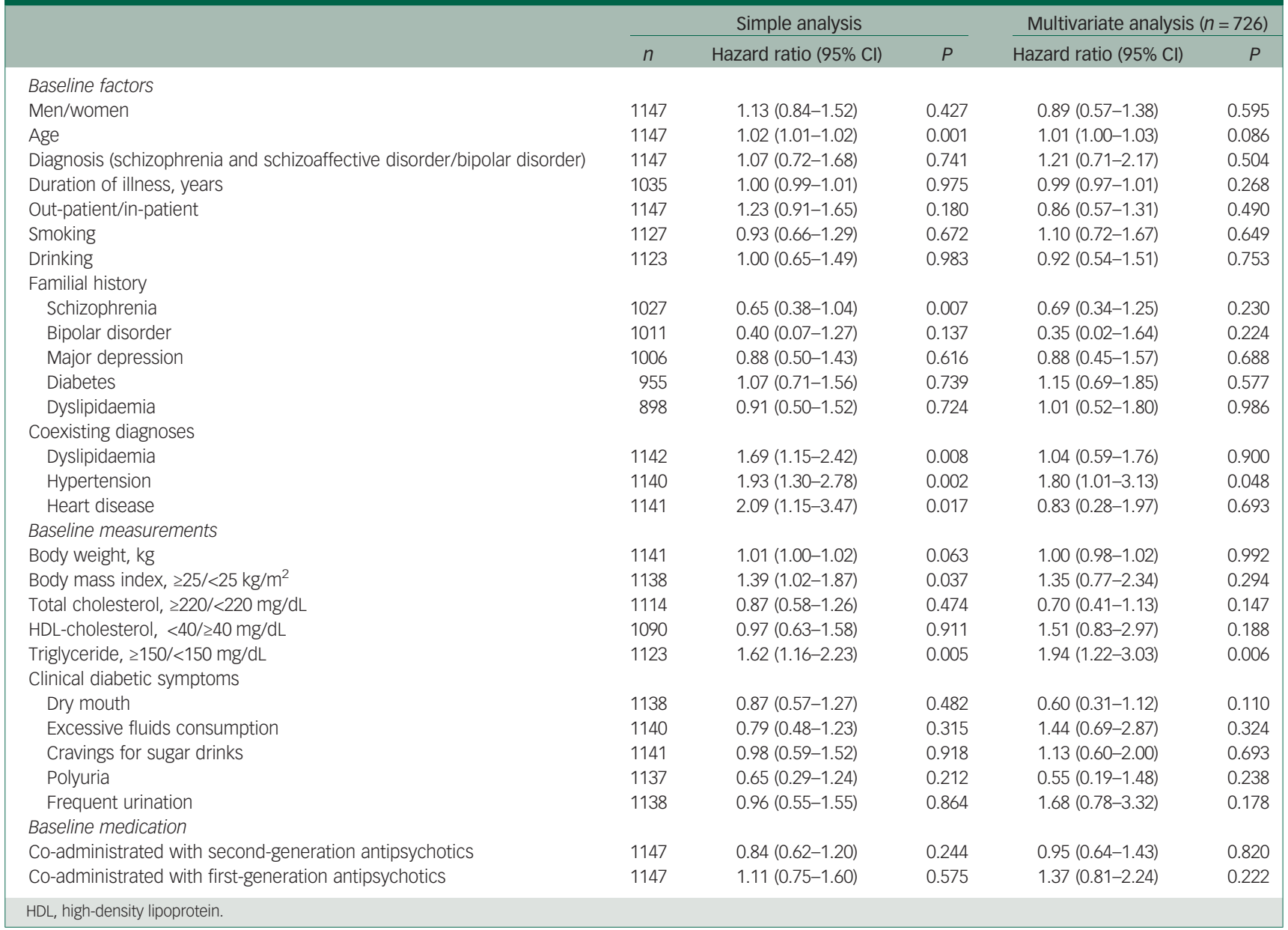

schizophrenia, schizoaffective disorder or bipolar disorder, and we identified elevated serum triglycerides and coexisting hypertension as such predictors. By comparing hyperglycaemic progression rates among patients receiving the six most frequently used antipsychotics in this study, we also confirmed our hypothesis that comprehensive longitudinal monitoring is essential in regular clinical practice irrespective of the antipsychotic used.

\section{Hypertension and diabetes}

Some cross-sectional studies have suggested a relationship between hypertension and diabetes in the general population, ${ }^{20,21}$ but prospective cohort studies have reported conflicting findings about whether individuals with hypertension are at an elevated risk for developing type 2 diabetes. ${ }^{22-24}$ In non-diabetic first-degree relatives of patients with type 2 diabetes, individuals with hypertension were no more likely to progress to type 2 diabetes than individuals without hypertension were. ${ }^{22}$ A prospective large-cohort Turkish study indicated that type 2 diabetes was significantly predicted by prehypertension (i.e. systolic blood pressure of $120-139 \mathrm{mmHg}$ or diastolic blood pressure of $80-89 \mathrm{mmHg}$ ) in women (relative risk 2.06) but not in men. ${ }^{23}$ A prospective cohort study of representative individuals aged 45-64 years suggested that type 2 diabetes was almost 2.5-fold more likely to develop in individuals with hypertension than in individuals with normal blood pressure. ${ }^{24}$ Hypertension and diabetes share many aetiological pathways with conditions such as obesity, inflammation, oxidative stress and insulin resistance. ${ }^{25}$ This study is the first to indicate that coexisting hypertension predicts diabetic progression in patients treated with antipsychotics who have schizophrenia or bipolar disorder.

\section{Diabetic progression during the follow-up period}

Of the patients with normal baseline glucose levels, 12.6 and 2.2\% were reclassified as having prediabetes and probable diabetes, respectively, over the 1-year follow-up period (Table 2). These

\begin{tabular}{|c|c|c|c|c|c|c|c|}
\hline & Aripiprazole & Olanzapine & Quetiapine & Risperidone & Perospirone & Blonanserin & Total \\
\hline Antipsychotic monotherapy at baseline, $n$ & 166 & 95 & 54 & 54 & 37 & 27 & 433 \\
\hline $\begin{array}{l}\text { Administration for more than } 10 \text { months, } n \\
\text { Change in diabetic state at final classification }{ }^{\text {a }}\end{array}$ & 71 & 54 & 23 & 22 & 15 & 9 & 194 \\
\hline No change, $n$ & 60 & 43 & 17 & 21 & 13 & 7 & 161 \\
\hline Hyperglycaemic progression, $n$ & 11 & 11 & 6 & 1 & 2 & 2 & 33 \\
\hline$\%, 95 \% \mathrm{Cl}$ & $15(9-26)$ & $20(12-33)$ & $26(12-46)$ & $5(1-22)$ & $13(4-38)$ & $22(6-55)$ & $17(12-23)$ \\
\hline
\end{tabular}


rates are consistent with those of our previous study, ${ }^{15}$ but the rate of progression from prediabetes to probable diabetes was much lower in the present study (18.8\%) than in our previous study (42.4\%). This may be because a greater proportion of participants completed the 1-year follow-up period in this study (1018 out of $1166,87.3 \%$ ) than in our previous study (374 out of $537,69.6 \%$ ). Our previous study's results might have been more subject to bias because of missing data. The current study had fewer missing data, probably because of the systematic feedback system for physicians that included reminders from the data management centre to report complete 1-year follow-up data. Because the physicians were thus prompted to monitor their patients more thoroughly, they were probably more likely to discover prediabetic states and encourage healthy diets and exercise as necessary. This could have prevented progression from prediabetes to probable diabetes. These results suggest that strict longitudinal monitoring is important for predicting and identifying the progression of diabetes and other glucose abnormalities in patients treated with antipsychotics who have schizophrenia or bipolar disorder.

\section{Effect of antipsychotics on diabetic progression}

In this study, hyperglycaemic progression rates over the 1-year observation period did not significantly differ among the six most frequently used antipsychotics. This finding can be explained by noting that this is an observational study, not a randomised controlled study, and that clinicians usually prescribe low-risk drugs to patients at high risk for diabetic progression. In contrast to the results of the CATIE study, ${ }^{14}$ these prescription biases might have reduced our ability to identify diabetic progression induced by high-risk antipsychotics such as clozapine and olanzapine and increased the apparent risk associated with low-risk antipsychotics such as aripiprazole. ${ }^{17}$ Thus, irrespective of the antipsychotic used, comprehensive longitudinal monitoring is essential in regular clinical practice.

\section{Strengths and limitations of the study}

Important strengths of this study were its nationwide, relatively large sample; strict longitudinal monitoring based on the Japanese guidelines in real clinical settings; and its examination of the effect of antipsychotics on diabetic progression. Although various limitations of our previous study ${ }^{15}$ were overcome in the present study, a 1-year follow-up period might have been insufficient for observing diabetic progression. Furthermore, our analyses of the effects of specific antipsychotics on hyperglycaemic progression relied on data from only a subset of the patient sample because most patients took more than one antipsychotic for at least a short period during this study. Relatively few Japanese people are severely obese, ${ }^{26}$ but even mild obesity may lead to hyperglycaemia in Japanese individuals. ${ }^{27}$ Therefore, our results may not be generalisable to Western populations, but our study's focus on a nonWestern population is also a strength because few studies have been conducted outside the USA and Europe. Future studies should use longer follow-up periods and larger samples.

\section{Implications for clinical practice and research}

High baseline serum triglycerides and coexisting hypertension are important predictors of diabetic progression in patients treated with antipsychotics who have schizophrenia or bipolar disorder. Irrespective of the antipsychotic used, comprehensive longitudinal monitoring is essential in regular clinical practice.

Ichiro Kusumi, MD, PhD, Professor, Department of Psychiatry, Hokkaido University Graduate School of Medicine, Japan; Yuki Arai, MD, Doctor, Department of Psychiatry, Wakkanai City Hospital, Japan; Ryo Okubo, MD, PhD, Doctor, Department of Psychiatry,
Hokkaido University Graduate School of Medicine and Honda Memorial Hospital, Japan; Minoru Honda, MD, PhD, Doctor, Honda Memorial Hospital, Japan;

Yasuhiro Matsuda, MD, PhD, Assistant Professor, Department of Psychiatry, Nara Medical University, Japan; Yukihiko Matsuda, MD, PhD, Vice Director, Hosogi Unity Hospital, Japan; Akihiko Tochigi, MD, Doctor, Tomakomai Midorigaoka Hospital, Japan; Yoshiteru Takekita, MD, PhD, Lecturer, Department of Neuropsychiatry, Kansai

Medical University, Japan; Hiroyoshi Yamanaka, MD, Doctor, Okamoto Hospital, Japan; Keiichi Uemura, MD, Doctor, Department of Psychiatry, Sapporo City General Hospital, Japan; Koichi Ito, MD, PhD, Vice Director, Sapporo Hanazono Hospital, Japan; Kiyoshi Tsuchiya, MD, PhD, Director, Tomakomai Midorigaoka Hospital, Japan; Jun Yamada, MD, Doctor, Kei-ai Hospital, Japan; Bunta Yoshimura, MD, Doctor, Okayama Psychiatric Medical Center, Japan; Nobuyuki Mitsui, MD, PhD, Assistant Professor, Department of Psychiatry, Hokkaido University Graduate School of Medicine and Department of Psychiatry, Wakkanai City Hospital, Japan; Sigehiro Matsubara, MD, PhD, General Manager, Department of Neuropsychiatry, Obihiro National Hospital, Japan; Takayuki Segawa, MD, Doctor, Okamoto Hospital, Japan; Nobuyuki Nishi, MD, PhD, Director, Nishi Hospital, Japan; Yasufumi Sugawara, MD, Doctor, Teine Hospital, Japan; Yuki Kako, MD, PhD, Lecturer, Department of Psychiatry, Hokkaido University Graduate School of Medicine, Japan; Ikuta Shinkawa, MD, Doctor, Okayama Psychiatric Medical Center, Japan; Kaoru Shinohara, MD, PhD, Director, Sapporo Suzuki Hospital, Japan; Akiko Konishi, MD, Doctor, Okayama Psychiatric Medical Center, Japan; Junichi Iga, MD, PhD, Associate Professor, Department of Psychiatry, Tokushima University and Department of Psychiatry, Ehime University, Japan; Naoki Hashimoto, MD, PhD, Associate Professor, Department of Psychiatry, Hokkaido University Graduate School of Medicine, Japan; Shinsaku Inomata, MD, Manager, Hizen Psychiatric Center, Japan; Noriko Tsukamoto, MD, Doctor, Hakodate Watanabe Hospital, Japan; Hiroto Ito, PhD, Director, National Institute of Occupational Safety and Health, National Center of Neurology and Psychiatry, Japan; Yoichi M. Ito, PhD, Associate Professor, Department of Biostatistics, Hokkaido University Graduate School of Medicine, Japan; Norihiro Sato, $\mathrm{MD}$, PhD, Professor, Hokkaido University Hospital Clinical Research and Medical Innovation Center, Japan

Correspondence: Ichiro Kusumi MD, PhD, North 15, West 7, Kita-Ku, Sapporo 060-8638, Japan. Email: ikusumi@med.hokudai.ac.jp

First received 24 Nov 2017, final revision 26 Jun 2018, accepted 22 Aug 2018

\section{Funding}

This study was supported by Early-Phase/Exploratory or International-Standard Clinical Research grants from the Japan Agency for Medical Research and Development (16lk0103005h0005). The funding sources had no role in the design or conduct of the study; collection, management, analysis, or interpretation of the data; preparation, review, or approval of the manuscript; or the decision to submit the manuscript for publication.

\section{Acknowledgements}

We thank the following people for substantial contributions to data acquisition: Drs H. Narita, Y. Nakato, S. Nakagawa, Y. Shimizu, T. Inoue, T. Saito, K. Kitagawa, Y. Fujii, S. Asakura, K. Toyoshima, R. Kameyama, Y. Wakatsuki, Y. Mizukami, Y. Hayashishita, and T. Tanaka of the Hokkaido University Graduate School of Medicine Department of Psychiatry (Sapporo, Japan): Drs S. Ikezawa, N. Kuroki, M. Ohmori, and K. Nakagome of the National Center of Neurology and Psychiatry Department of Psychiatry (Kodaira, Japan); Drs H. Muraoka, T. Kohno, K. Takahashi, and J. Ishigooka of the Tokyo Women's Medical University Department of Psychiatry (Tokyo, Japan); Drs H. Watanabe and M. Iyo of the Chiba University Department of Psychiatry (Chiba, Japan); Dr S. Miyamoto of the St. Marianna University School of Medicine Department of Psychiatry (Kawasaki, Japan); Dr K. Hatta of the Juntendo University Nerima Hospital Department of Psychiatry (Tokyo, Japan); Drs S. Ozaki and M. Okumura of the Toshima Hospital Department of Psychiatry (Tokyo, Japan); Drs T. Kikuchi and K. Watanabe of the Kyorin University Department of Psychiatry (Mitaka, Japan); Drs H. Yoshino, S. Ueda, K. Ikeshita, Y. Nakanishi, and T. Kishimoto of the Nara Medical University Department of Psychiatry (Nara, Japan); Drs Y. Koshikawa and T. Kinoshita of the Kansai Medical University Department of Neuropsychiatry (Moriguchi, Japan); Drs S. Watabe, H. Kubo, N. Kameoka, T. Tominaga, and T. Ohmori of the Tokushima University Department of Psychiatry (Tokushima, Japan); Drs K. Kawabe, N. Sonobe, Y. Miyama, H. Shimizu and S. Ueno of the Ehime University Department of Psychiatry (Matsuyama, Japan); Drs A. Kozuki, R. Yoshimura, A. Sugita and $\mathrm{H}$. Hori of the University of Occupational and Environmental Health Department of Psychiatry (Kitakyusyu, Japan); Dr T. Ueno of the Hizen Psychiatric Center (Kanzaki, Japan); Drs Y. Yada, K. Bessho, T. Horikoshi, Y. Mitsui, H. Itakura, Y. Kokoroishi, K. Sato, M. Fujiwara, M. Chida, R. Sou, M. Takase, K. Makino, Y. Kishi, T. Sunami, S. Ikeda, T. Kohno, and T. Miyake of the Okayama Psychiatric Medical Center (Okayama, Japan); Dr K. Suzuki of the Aomori Prefectural Central Hospital Department of Psychiatry (Aomori, Japan); Drs H. Tanii and M. Okada of the Mie University Department of Psychiatry (Tsu, Japan): Drs T. Hirooka and $\mathrm{H}$. Miyaoka of the Kitazato University East Hospital Department of Psychiatry (Sagamihara, Japan); Drs K. Fujita, I. Yasue, S. Tanaka, M. Hattori, A. Okuda, R. Suzuki, K. Miyahara, M. Yonehara, R. Tsuji, G. Cho, K. Okada, N. Kimura, M. Takagi, T. Mekata, M. Hirano, and S. Takeichi of the Okehazama Hospital (Toyoake, Japan); Drs R. Matsubara, Y. Usukubo, R. Nozawa, and T. Fujie of the Sapporo Hanazono Hospital (Sapporo, Japan); Drs S. lizuka, M. Sato, T. Isoyama, C. Ikeda, A. Mikami, and Y. Hyakkan of the Hakodate Watanabe Hospital (Hakodate, Japan); Drs N. Okamoto, Y. Niwa, and T. Suzuki of the Sapporo Suzuki Hospital (Sapporo, Japan); Dr K. Nakajima of the Yakumo General Hospital Department of Psychiatry (Yakumo, Japan); Dr S. Tsuchida of the Kutchan-Kosei General Hospital Department of Psychiatry (Kutchan, Japan); Drs Y. Kamikawa and N. Morita of the Kei-ai Hospital (Noboribetsu, Japan); Dr T. Takeuchi of the Tomakomai Midorigaoka Hospital (Tomakomai, Japan); Drs H. Takeshige and T. Maeda of the Hokkaido Koyogaoka Hospital (Abashiri, Japan): Drs T. Egashira, M. Oka, and H. Umezu of the Wakkana City Hospital Department of Psychiatry (Makkanai, Japan); Drs A. Ito and A. Mikami of the Muroran City General Hospital Department of Psychiatry (Muroran, Japan); Drs S. Miyano and 
H. Sawayama of the Teine Hospital (Sapporo, Japan); Drs T. Ishikane, M. Kohsaka, and H. Mieda of the Ishikane Hospital (Sapporo, Japan): Dr T. Hayashishita of the Hayashishita Hospital (Sapporo, Japan): Dr T Komiyama of the lida Hospital (lida, Japan); Drs Y Oyanagi, H. Honma, M. Okumura, Y Hosokawa, Y Umemoto, and T. Horinouchi of the Obihiro National Hospital Department of Neuropsychiatry (Obihiro, Japan); Dr I. Suzuki of the Sapporo Kokoronomori Clinic (Sapporo, Japan); Dr T. Matsuyama of the Okamoto Hospital (Sapporo, Japan); Dr Y. Maki of the Maki Hospital (Iwamizawa, Japan); and Drs T. Tao and J. Watanabe of the Oyachi Hospital (Sapporo, Japan). The following project staff from the Hokkaido University Hospital Clinical Research and Medical Innovation Center provided outstanding support for this project: T. Miyakoshi, A. Hirai, S. Tanno, C. Nishimura, and C. Asano, who assiste database management, and $T$. Amano and $K$. Ono, who assisted with statistical analysis. Editage (www.editage.jp) assisted with English-language editing.

\section{References}

1 Laursen TM, Wahlbeck K, Haellgren J, Westman J, Oesby U, Alinaghizadeh $\mathrm{H}_{\text {, }}$ et al. Life expectancy and death by diseases of the circulatory system in patients with bipolar disorder or schizophrenia in the Nordic countries. PLOS One 2013; 8: e67133.

2 Ifteni P, Correll CU, Burtea V, Kane JM, Manu P. Sudden unexpected death in schizophrenia: autopsy findings in psychiatric inpatients. Schizophr Res 2014; 155: 72-6.

3 Sweeting J, Duflou J, Semsarian C. Postmortem analysis of cardiovascular deaths in schizophrenia: a 10-year review. Schizophr Res 2013; 150: 398-403.

4 Stubbs B, Vancampfort D, De Hert M, Mitchell AJ. The prevalence and predictors of type two diabetes mellitus in people with schizophrenia: a systemic review and comparative meta-analysis. Acta Psychiatr Scand 2015; 132 144-57.

5 Vancompfort D, Mitchell AJ, De Hert M, Sienaert P, Probst M, Buys R, et al. Prevalence and predictors of type 2 diabetes mellitus in people with bipolar disorder: a systemic review and meta-analysis. J Clin Psychiatry 2015; 76 : 1490-9.

6 Sarwar N, Gao P, Seshasai SR, Gobin R, Kaptoge S, Di Angelantonio E, et al. Diabetes mellitus, fasting blood glucose concentration, and risk of vascular disease: a collaborative meta-analysis of 102 prospective studies. Lancet 2010; 375: 2215-22

7 Leucht S, Corves C, Arbter D, Engel RR, Li C, Davis JM. Second-generation versus first-generation antipsychotic drugs for schizophrenia: a meta-analysis. Lancet 2009; 373: 31-41.

8 Graham KA, Cho H, Brownley KA, Harp JB. Early treatment-related changes in diabetes and cardiovascular disease risk markers in first episode psychosis subjects. Schizophr Res 2008; 101: 287-94.

9 Newcomer JW. Abnormalities of glucose metabolism associated with atypical antipsychotic drugs. J Clin Psychiatry 2004; 65: 36-46.

10 Kusumi I, Ito K, Honda M, Hayashishita T, Uemura K, Hashimoto $N$, et al. Screening for diabetes using Japanese monitoring guidance in schizophrenia patients treated with second-generation antipsychotics: a cross-sectional study using baseline data. Psychiatry Clin Neurosci 2011; 65: 349-55.

11 Okumura $\mathrm{Y}$, Ito $\mathrm{H}$, Kobayashi $\mathrm{M}$, Miyahara $\mathrm{K}$, Matsumoto $\mathrm{Y}$, Hirakawa J. Prevalence of diabetes and antipsychotic prescription patterns in patients with schizophrenia: a nationwide retrospective cohort study. Schizophr Res 2010; 119: 145-52.
12 Van Winkel R, De Hert M, Van Eyck D, Hanssens L, Wampers M, Scheen A, et al. Screening for diabetes and other metabolic abnormalities in patients with schizophrenia and schizoaffective disorder: evaluation of incidence and screening method. J Clin Psychiatry 2006; 67: 1493-500.

13 de Leon J, Diaz FJ. Planning for the optimal design of studies to personalize antipsychotic prescriptions in the post-CATIE era: the clinical and pharmacoepidemiological data suggest that pursuing the pharmacogenetics of metabolic syndrome complications (hypertension, diabetes mellitus and hyperlipidemia) may be a reasonable strategy. Schizophr Res 2007; 96: 185-97.

14 Meyer JM, Davis VG, Goff DC, McEvoy JP, Nasrallah HA, Davis SM, et al. Change in metabolic syndrome parameters with antipsychotic treatment in the CATIE schizophrenia trial: prospective data from phase 1. Schizophr Res 2008; 101 : 273-86.

15 Kusumi $\mathrm{I}$, Ito $\mathrm{K}$, Uemura $\mathrm{K}$, Honda $\mathrm{M}$, Hayashishita $\mathrm{T}$, Miyamoto $\mathrm{K}$, et al. Screening for diabetes using monitoring guidance in schizophrenia patients treated with second-generation antipsychortics: a 1-year follow-up study. Prog Neuropsychopharmacol Biol Psychiatry 2011; 35: 1922-6.

16 Cohn TA, Sernyak MJ. Metabolic monitoring for patients treated with antipsychotic medications. Can J Psychiatry 2006; 51: 492-501.

17 American Diabetes Association, American Psychiatric Association, American Association of Clinical Endocrinologists, North American Association for the Study of Obesity. Consensus development conference on antipsychotic drugs and obesity and diabetes. J Clin Psychiatry 2004; 65: 267-72.

18 World Health Organization. The ICD-10 Classification of Mental and Behavioural Disorders: Clinical Descriptions and Diagnostic Guidelines. WHO, 1992.

19 Cox DR. Regression models and life-tables. J R Stat Soc Series B Stat Methodol 1972; 34: 187-220.

20 Henry P, Thomas F, Benetos A, Guize L. Impaired fasting glucose, blood pressure and cardiovascular disease mortality. Hypertension 2002; 40: 458-63.

21 limura O. Insulin resistance and hypertension in Japanese. Hypertens Res 1996; 19: S1-S8.

22 Janghorbani M, Amini M. Progression from optimal blood glucose and pre-diabetes to type-2 diabetes in a high risk population with or without hypertension in Isfahan, Iran. Diabetes Res Clin Pract 2015; 108: 414-22.

23 Onat A, Yazici M, Can G, Kaya Z, Bulur S, Hergenc G. Predictive value of prehypertension for metabolic syndrome, diabetes, and coronary heart disease among Turks. Am J Hypertens 2008; 21: 890-5.

24 Gress TW, Nieto FJ, Shahar E, Wofford MR, Brancati FL. Hypertension and antihypertensive therapy as risk factors for type 2 diabetes mellitus. $N$ Engl J Med 2000; 342: 905-12.

25 Cheung BMY, Li C. Diabetes and hypertension: is there a common metabolic pathway? Curr Atheroscler Rep 2012; 14: 160-6.

26 Japanese Ministry of Health. Labour and Welfare: The National Health and Nutrition Survey in Japan [in Japanese]. Japanese Ministry of Health, 2012 (http://www.mhlw.go.jp/bunya/kenkou/eiyou/dl/h24-houkoku.pdf).

27 Yoshiike $\mathrm{N}$, Nishi $\mathrm{N}$, Matsushima $\mathrm{S}$, Ito $\mathrm{C}$, Ikeda $\mathrm{Y}$, Kashihara $\mathrm{H}$, et al. Relationship between severity of obesity based on body mass Index and risk factors of diabetes, hypertension and hyperlipidemia: a multisite, collaborative, epidemiological study [in Japanese]. Obesity Res 2000; 6: 4-17.

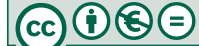

